\title{
NARROW RIDGE EXPANSION FOR IMPLANT PLACEMENT USING ULTRASONIC BONE SURGERY AND PLATELET RICH FIBRIN WITH AND WITHOUT SILK FIBROIN
}

\author{
Ramy Salah Hamed **, Mahmoud Taha Eldestawy**, Usama Mohammed Madany***
}

\begin{abstract}
Objective: To evaluate the effect of combined split-crest technique using ultrasonic bone surgery with platelet rich fibrin alone and in combination with silk fibroin for dental implant placement in narrow ridge. Materials and Methods: A total of 24 implants (NUCLOSS T6) inserted in 18 patients with narrow alveolar ridge. Patients were assigned randomly into one of the following 2 groups based on the graft material used. For group I, the peri implant gap was filled with silk fibroin mixed with PRF while for group 2 was filled with PRF only. All patients undergone a ridge splitting technique using piezoelectrical surgical device and immediate implant placment. Assessments included measurements of the alveolar ridge width, implant stability and bone density. Results: Success rate of implants at the end of follow-up was $100 \%$. However, the differences in implant stability measurements were non- significant in both groups at baseline, at 6 months the difference was statistical significance $(P 0.001=)$ in favor of silk fibroin group. Additionally, the differences in mean alveolar crest width measurements between both studied groups, were statistically non- significant at base line and immediately after surgery while silk fibroin group exhibited a statistically significant $(P 0.010=)$ increase in mean alveolar crest width measurements at 6 months. Moreover, silk fibroin group also showed higher and statistically significant $(P 0.001=)$ mean bone density measurements, at 6 months compared to PRF group. Conclusions: Compared to PRF alone, adding silk fibroin might provide a better reconstruction of ridge width, implant stability and bone density in the narrow ridge augmented with crest splitting and immediate implants.
\end{abstract}

KEY WORDS: Ridge expansion, split-crest, ultrasonic bone surgery, silk fibroin, platelet rich fibrin.

\section{INTRODUCTION}

Dental rehabilitation of edentulous patients with implants has become common practice in the last few decades. Unfortunately local conditions of some alveolar ridges of such patients may be challenge for implant placement. One of these conditions is a relevant horizontal deficit which may render the use of dental implants difficult or impossible ${ }^{(1)}$. Several solutions were presented to overcome this challenge as, guided bone regeneration techniques ${ }^{(2)}$ and bone block techniques ${ }^{(3)}$. However, these techniques have many shortages that might be overcome by splitcrest augmentation technique ${ }^{(4)}$. Ridge splitting/ expansion is an alternative technique to treat the width insufficiency of alveolar ridges with specific

\footnotetext{
* Masters Candidate, Dentist at Ministry of Health

** Assistant Professor, Department of Oral Medicine, Periodontology, Diagnosis and Oral Radiology Faculty of Dental Medicine, Boys ,Cairo, Al-Azhar University

*** Professor, Department of Oral Medicine, Periodontology, Oral Diagnosis and Oral Radiology Vice Dean, Faculty of Dental Medicine, Boys, Cairo, Al-Azhar University
}

-Corresponding author: dr.ramyimam@gmail.com

DOI: $10.21608 /$ ajdsm.2020.26649.1049 
indications. In 1986, Nentwig ${ }^{(5)}$ reported a bone crest division technique that simultaneously allowed the expansion of the alveolar crest and implant insertion. Ultrasonic devices have the ability to cut mineralized hard tissues as teeth or bone in a very safe and precise way, with minor tissue damage. Soft tissues such as $\backslash$ nerves, blood vessels, or the Schneiderian membrane are not altered by the cutting tip because of their ability to oscillate at the same speed and amplitude as the cutting tip ${ }^{(6)}$.

The greenstick separation of the deficient (often collapsed) buccal cortical plate from the palatal or lingual portion of the alveolar bone in split crest technique leads to an opening of bony gap (like the slow opening of a book) which mainly occupied by immediately inserted implant. If the peri-implant gap is more than $1.5 \mathrm{~mm}$, the second aspect of split crest technique is grafting. Material originating from autogenous blood can be used as filling material for the peri implant gap instead of autogenous bone, in which case donor site morbidity and operating time can be reduced. Platelet rich fibrin (PRF) has been widely used for this purpose. It can be used alone $\mathrm{e}^{(7-9)}$ or in combination with other biomaterials ${ }^{(10,11)}$. Platelet-rich fibrin (PRF) has numerous growth factors and cytokines, which accelerate early bone regeneration by increased angiogenesis, chemotaxis, mitosis, and stem cell proliferation ${ }^{(12)}$. However, the ability of PRF to augment and regenerate compromised tissues may be enhanced when mixed with bone grafts or substitutes. Although, autograft, allograft, xenograft, and alloplast all have reported success in combination with PRF for bone augmentation, limitations related to each of them have been reported ${ }^{(13)}$. Most commercially available alloplasts are based on calcium phosphate, ceramics, titanium, or bioactive glasses. Despite their advantages, they often fail to fulfill all the desired requirements for bone regeneration. They lack durability, a match of mechanical properties with surrounding tissue and an appropriate rate of resorption. Additionally, when used alone, they often yield suboptimal bone turnover. Therefore, a wide variety of novel alloplastic materials and methods are still being developed and suggested based on tissue engineering techniques for bone regeneration ${ }^{(14)}$.

Natural silk fibroin fiber is one of the strongest and toughest materials known with superior biomechanical properties. It is a fibrous protein produced mainly by silkworms, spiders, bees, and flies. However, Bombyx mori (B. mori) silkworms are the main producer of silk worldwide ${ }^{(15)}$. Structurally, silk fibroin consists mainly of two major proteins, fibroin (fibrous protein $72-81 \%$ ) and Sericin (globular protein 19-38\%). Inflammatory reactions which come mainly from Sericin are the main concern related to silk grafts. Fortunately, pure silk fibroin causes less of this type of reaction ${ }^{(15)}$. Being a protein, silk fibroin can be enzymatically degraded in vivo by various tissue enzymes such as protease XIV, alpha chymotrypsin and collagenase IA, and the resulting amino acids can be biologically absorbed. To slow down the degradation rate, protease inhibitors can be integrated into silk based systems $^{(16)}$. Furthermore, biodegradability is related to the molecular weight, the small fragments of silk fibroin may degrade more rapidly and cause less inflammation compared with macromolecules ${ }^{(15)}$. This unique properties such as, slow biodegradation, superior mechanical properties, favorable processability in combination with biocompatibility, enable silk fibroin to act as a scaffold providing support for cells until they are organized into a functional tissue through migration, proliferation, differentiation and deposition of extracellular matrix ${ }^{(17)}$. By reviewing the literature, no study dealing with mixing of PRF and silk fibroin for filling the peri implant gab in humans has been published yet. In the present study, silk fibroin powder was used as a combination template with PRF for the restoration of bony defect gap around implants as a clinical trial to possibly enhance the clinical outcomes expected by PRF alone. 


\section{MATERIALS AND METHODS}

This study was carried out as a randomized clinical trial and was conducted on eighteen patients of both sexes ( 8 males and 10 females; age range: 20 to 50 years) with narrow ridge ${ }^{(18)}$, The sample was selected conveniently to fulfill the following criteria. Adults (ageing 20-50). exhibiting insufficiently alveolar ridge width $(<4 \mathrm{~mm})$ at the alveolar crest concluded from pre-CBCT scans ${ }^{(19)}$. Patients with good oral hygiene and free from systemic diseases that may influence the outcome of the therapy ${ }^{(20)}$. Patients with sufficient vertical dimension of alveolar ridge and have not a history of any grafting procedure at the designated edentulous ridge.

Clinical examination including medical and dental history, general and oral health status and assessment of future implant site was performed to each patient. Radiographic evaluation was done using cone beam computed tomography (CBCT) scan as a final investigation and treatment plane preparation. With in-vivo dental software, it was possible to correctly assess the bucco-lingual width of each implant site. Prior to the surgery, each patient was given careful instructions on proper oral hygiene measures. Full mouth supra- and subgingival scaling and root planning procedures were performed in quadrants under local anesthesia.

\section{Patients grouping}

The selected eighteen participants then were randomly assigned in two equal groups each consisting of 9 patients. Group I: Received split-crest technique by ultrasonic bone surgery and implant placement grafted with silk fibroin mixed with PRF. Group 2: Received split-crest technique by ultrasonic bone surgery and implant placement grafted with PRF only

\section{Pre surgical medication}

The patients were initiated on a daily dose of antibiotic $^{\Omega}$ (amoxicillin plus clavulanic acid twice daily about $20-25 \mathrm{mg} / \mathrm{kg} /$ day), one day prior to surgery as prophylactic. One tablet from Ibuprofen ${ }^{\odot}$ $400 \mathrm{mg}$ and Paracetamol ${ }^{€} 500 \mathrm{mg}$ were given to the patients an hour before surgery. If necessary, one tablet of midazolam $7.5 \mathrm{mg}$ was administered 20 minutes before the intervention to promote patient relaxation and facilitate his/her collaboration ${ }^{(21)}$.

\section{Surgical procedures}

Surgical procedures were undergone under local anaesthesia using articaine hydrochloride $4 \%$ and levonordefrin*. Following administration of local anesthesia, paracrestal incision was made by blade ${ }^{\circledR}$ number $15 \mathrm{c}$ and a full thickness flap of the summit of the bone ridge was elevated using mucoperiosteal elevator then continued with a partial thickness flap in the vestibular fornix. Vertical releasing incisions were performed when deemed necessary. The longitudinal mesiodistal midcrestal osteotomy was performed using the CS1 and CS2 tips from the Crest-Splitting Kit of Peizotome Solo Led. The conical CS4, CS5 and CS6 tips from the CrestSplitting Kit were then used gradually to increase the resulting osteotomy-gap from 1 to $3.75 \mathrm{~mm}$. After sufficient lateralization of the buccal plate the implant sites were prepared with progressive twist drills up to the pre_implant size drill then the bone expander corresponding to the implant size was used to obtain an apical implant preparation of about $3 \mathrm{~mm}$ beyond the depth of the horizontal cut to get primary stability of the implants.

NucleOSS two-stage implant system was used in this study with length ranged from $10 \mathrm{~mm}$ to $14 \mathrm{~mm}$, and diameter of $3.5 \mathrm{~mm}$. The implants were inserted within the splitted ridge using manual key and ratchet with average torque measuring about 25-30 $\mathrm{N}$. The implant primary stability was then recorded at the baseline using Osstell ISQ. A blood sample of $10 \mathrm{ccs}$ was obtained from the patient for each single implant to obtain the PRF clot. The PRF clots were cut to fulfill the gap between the separated plates of bone for the PRF group. For silk fibroin group, silk fibroin powder ${ }^{\infty}$ (Low-molecular- weight silk fibroin powder (molecular weight $0.5-1.0 \mathrm{kDa}$ )) 
mixed with PRF (0.5:1 by volume respectively) and packed into inter positional spaces using titanium applicator. Finally, a periosteal releasing incision were performed in order to obtain tension free wound closure and to compensate for increased ridge width.

\section{Post-surgical management}

The patients were placed on a systemically administered anti edematous agent thrice daily have an hour before meals and maintained on the dose of antibiotic for the next 5-7 days after surgery. CBCT scans were taken immediately after surgery completion and at 6 months to evaluate ridge width as well as bone density. Suture was removed at 10 to 14 days. At 6 months implant exposure was done. Implant stability was recorded. CBCT images were viewed with a $3^{\text {rd }}$ party Software; the In Vivo, Dental Application, Version.5.31. Visualization tools (contrast, brightness, magnification lens and window level) were used to optimize the viewing condition. Before interpretation and measurements, aligned protocol setting were done "re-orientation of the orthogonal images was done so that the sagittal plane $(\mathrm{Y})$ is oriented parallel to the long axis of the Implant under examination". When this was done, automatically the coronal plane would be set perpendicular to the long axis of the implant. The image was then lined up with the visible dot representing the internal void of implant fixture parallel to the mid-sagittal plane." The thickness of the alveolar bone was measured after selecting the cross-sectional image made at the midpoint of the implant. Measurements of ridge width were taken at the bone crest levels at the time of implant placement and at 6 months post-treatment ${ }^{(22)}$. For measuring the bone density standard rectangular shape was drown mesial and distal to the implant with average of $10 \mathrm{~mm}$ to $12 \mathrm{~mm}$ length and $1.5 \mathrm{~mm}$ to $1.7 \mathrm{~mm}$ width. The gray values of the bone density around implant were measured in this two regions; mesial region and distal region immediately after surgery and at 6 months post-treatment ${ }^{(23)}$.

\section{RESULTS}

Fisher's exact test and student t test showed no statistically significant differences in gender distribution and mean of age respectively between the two studied groups (Table1) .

TABLE (1): Comparison between the two studied groups according to gender distribution and mean of age

\begin{tabular}{|c|c|c|c|c|c|c|}
\hline & \multicolumn{2}{|c|}{$\begin{array}{c}\text { PRF } \\
(n=12)\end{array}$} & \multicolumn{2}{|c|}{$\begin{array}{l}\text { Silk fibroin } \\
\quad(\mathrm{n}=12)\end{array}$} & \multirow{2}{*}{$\begin{array}{c}\text { Test of } \\
\text { Sig. }\end{array}$} & \multirow{2}{*}{$\mathbf{P}$} \\
\hline & No. & $\%$ & No. & $\%$ & & \\
\hline \multicolumn{7}{|l|}{ Sex } \\
\hline Male & 5 & 53.0 & 3 & 40.0 & \multirow{2}{*}{$\begin{array}{c}\chi^{2}= \\
0.202\end{array}$} & \multirow{2}{*}{$\begin{array}{c}{ }^{\mathrm{FE}} \mathrm{p}= \\
1.000\end{array}$} \\
\hline Female & 4 & 47.0 & 6 & 60.0 & & \\
\hline \multicolumn{7}{|l|}{ Age } \\
\hline Min. - Max. & \multicolumn{2}{|c|}{$29.0-45.0$} & \multicolumn{2}{|c|}{$28.0-42.0$} & \multirow{3}{*}{$\begin{array}{c}t= \\
1.494\end{array}$} & \multirow{3}{*}{0.152} \\
\hline Mean \pm SD & \multicolumn{2}{|c|}{$37.70 \pm 5.66$} & \multicolumn{2}{|c|}{$34.20 \pm 4.78$} & & \\
\hline Median & \multicolumn{2}{|c|}{38.50} & \multicolumn{2}{|c|}{34.0} & & \\
\hline
\end{tabular}

$\div^{2}$ : Chi square test

FE: Fisher Exact $t$ : Student t-test

$p: p$ value for comparing between the studied groups

\section{Clinical Results}

In PRF group, the mean ostell ISQ measurements were increased from $64.90 \pm 5.28$ immediately after surgery to $66.80 \pm 5.79$ at 6 months $(9.15 \pm 7.37)$. In silk fibroin group, the mean ostell ISQ measurements were increased from $63.80 \pm 3.22$ immediately after surgery to $76.80 \pm 3.65$ at 6 months $(12.99 \pm 2.27)$. The changes in both groups were statistically significant. According to student t-test, the differences in mean ostell ISQ measurements were non- significant in both groups at baseline. In contrast, at 6 months the differences showed statistical significance $\left(P \_0.001\right)$ in favor of silk fibroin group (Table 2$)$. 
TABLE (2): Student t-test results of ostell ISQ measurements at 6 months for the two studied groups.

\begin{tabular}{|c|c|c|c|c|c|c|}
\hline & \multicolumn{2}{|c|}{$\begin{array}{c}\text { PRF } \\
(\mathbf{n}=\mathbf{1 2})\end{array}$} & \multicolumn{2}{c|}{$\begin{array}{c}\text { Silk fibroin } \\
(\mathbf{n}=\mathbf{1 2})\end{array}$} & \multirow{2}{*}{ T } & \multirow{2}{*}{ p } \\
\cline { 2 - 4 } & Mean & \pm SD & Mean & \pm SD & & \\
\hline Ostell ISQ measurements \\
\hline $\begin{array}{c}\text { At base } \\
\text { line }\end{array}$ & 64.90 & 5.28 & 63.80 & 3.22 & 0.562 & 0.581 \\
\hline 3 months & 57.0 & 5.29 & 58.60 & 4.95 & 0.175 & 0.863 \\
\hline 6 months & 66.80 & 5.79 & 76.80 & 3.65 & $40.123^{*}$ & $<0.001^{*}$ \\
\hline
\end{tabular}

t: Student t-test

$p: p$ value for comparing between the studied groups

\section{Radiographic results}

The mean alveolar crest width measurements were $3.36 \pm 0.42,5.84 \pm 0.57$ and $5.22 \pm 0.38$ before surgery (pre), at base line (immediately after surgery) and 6 months repetitively in PRF group while in silk fibroin group, they were $3.56 \pm 0.30,6.16 \pm 0.44$ and $5.74 \pm 0.43$ at the same observation periods. At base line both groups, showed a statistically significant increase in mean alveolar crest width measurements (with percent change of $\uparrow 76.57 \pm 29.04$ for PRF group and $\uparrow 73.84 \pm 12.9$ for silk fibroin group). At 6 months both groups showed statistically nonsignificant decrease (with percent change of $\uparrow 58.41$ \pm 27.52 for PRF group and $\uparrow 62.12 \pm 13.40$ for silk fibroin group). The differences in mean alveolar crest width measurements between both studied groups, were statistically non- significant before surgery and at base line. Silk fibroin group exhibited a statistically significant $\left(P \_0.010\right)$ increase in mean alveolar crest width measurements at 6 months; (Table 3).
TABLE (3): Result analysis of alveolar width measurements according to student t-test for the two studied groups.

\begin{tabular}{|c|c|c|c|c|c|c|}
\hline & \multicolumn{2}{|c|}{$\begin{array}{c}\text { PRF } \\
(\mathbf{n}=\mathbf{1 2})\end{array}$} & $\begin{array}{c}\text { Silk fibroin } \\
(\mathbf{n = 1 2})\end{array}$ & \multirow{2}{*}{ T } & P \\
\cline { 2 - 5 } & Mean & \pm SD & Mean & \pm SD & & \\
\hline Width measurements \\
\hline Pre & 3.36 & 0.42 & 3.56 & 0.30 & 1.222 & 0.238 \\
\hline At base line & 5.84 & 0.57 & 6.16 & 0.44 & 1.422 & 0.172 \\
\hline 6 months & 5.22 & 0.38 & 5.74 & 0.43 & $2.864^{*}$ & $0.010^{*}$ \\
\hline
\end{tabular}

$t$ : Student t-test

p: $p$ value for comparing between the studied groups in each period

*: Statistically significant at $p \leq 0.05$

The mean bone density increased in both groups and were $130.3 \pm 262.3, \quad 345.5 \pm 179 \quad(54.87 \% \pm$ 151.9), and $143.45 \pm 278.3 .5,418.8 \pm 181.3(79.02 \%$ $\pm 241)$, immediately after surgery and at 6 months in PRF group and silk fibroin group respectively. The changes in both groups were statistically significant. Silk fibroin group showed higher and statistically significant $\left(P \_0.001\right)$ mean bone density measurements, at 6 months compared to PRF group; (Table 4).

TABLE (4): Mann Whitney test for the two studied groups according to bone density.

\begin{tabular}{|c|c|c|c|c|c|c|}
\hline & \multicolumn{2}{|c|}{$\begin{array}{c}\text { PRF } \\
(\mathbf{n}=\mathbf{1 2})\end{array}$} & $\begin{array}{c}\text { Silk fibroin } \\
(\mathbf{n}=\mathbf{1 2})\end{array}$ & \multirow{2}{*}{ U } & P \\
\cline { 2 - 4 } & Mean & \pm SD & Mean & \pm SD & & \\
\hline Relative bone Density \\
\cline { 1 - 2 } $\begin{array}{l}\text { Immediately } \\
\text { after surgery }\end{array}$ & 130.3 & 262.3 & 143.4 & 278.3 & 36.50 & 0.315 \\
\hline 6 months later & 345.5 & 179.5 & 418.8 & 181.3 & $39.342^{*}$ & $<0.001^{*}$ \\
\hline
\end{tabular}

U: Mann Whitney test

$p: p$ value for comparing between the studied groups 


\section{DISCUSSION}

Due to bone resorption that possibly happens after teeth extraction, ideal placement of implants may sometimes be impossible without hard and soft tissue augmentation. While several techniques are available, the split crest techniques allow for one-stage bone expansion and implant placement. Bony gap are always a problem if an immediate implant installation is to occur. In the present study, silk fibroin mixed with PRF or PRF alone were successfully applied to peri-implant bony gap remained after immediate implant installation in expanded alveolar ridge. In the present study, we evaluated the capability of silk fibroin as a biomaterial template for bone regeneration when mixed with Choukroun PRF in vivo. Also, the results were compared with the ability of PRF alone. The combination graft showed higher implant stability as reveled through ostell ISQ values $(9.15 \%$ for PRF and $12.99 \%$ for PRF+ SF) and higher relative bone density (54.87 \% for PRF and 79.02 for PRF+ SF) as well as greater maintenance of gained alveolar ridge width.

This might be due to the fact that Choukroun PRF is known to release growth factors for at least 7 days ${ }^{(24)}$. For the prolonged release of the growth factors, a proper scaffold may be required. Silk fibroin has been widely studied as a scaffold material ${ }^{(25)}$. However, Biomaterials such as bioactive glass $^{(26)}$ or hydroxyapatite can also be used they are not completely biodegradable while, Silk fibroin powder was not found in the section 8 weeks after the operation in the study performed by Jang et al. ${ }^{(27)}$ to evaluate the bone regenerative effect of silk fibroin mixed with platelet-rich fibrin in the parietal bone of New Zealand rabbits. Moreover, the remarkable mechanical properties of silk fibroin enable from acting as scaffolds provide biomechanical support for cells until they are organized into a functional tissue through migration, proliferation, differentiation and deposition of extracellular matrix ${ }^{(17)}$.
According to our finding, the mean alveolar crest width measurements increased significantly from $3.36 \pm 0.42$ at base line to $5.84 \pm 0.57$ immediately after surgery $(\uparrow 76.57 \% \pm 29.04)$, then decreased insignificantly to $5.22 \pm 0.38$ at 6 months $(\uparrow 58.41 \%$ $\pm 27.52)$ In PRF group. In silk fibroin group, the mean alveolar crest width measurements increased significantly from $3.56 \pm 0.30$ at base line to $6.16 \pm$ 0.44 immediately after surgery $(\uparrow 73.84 \% \pm 12.9)$, then decreased insignificantly to $5.74 \pm 0.43$ at 6 months $(\uparrow 62.12 \% \pm 13.40)$ at 6 months. These expected results came in correspondence with previous studies by Elnayef et al. ${ }^{(28)}$ Waechter et al. ${ }^{(29)}$ Cortese et al. ${ }^{(30)}$ who strongly support the use of split crest technique with piezoelectric surgery for implant placement in narrow ridge. In regard to bone density, silk fibroin group showed higher and statistically significant $\left(P \_0.001\right)$ mean bone density measurements, at 6 months compared to PRF group. These results came in correspondence with the results of previous studies ${ }^{(31,32)}$ suggested that the combination of silk fibroin and growth factors contained in PRF may be suitable to enhance bone density. According to student t-test, the differences in mean ostell ISQ measurements were non- significant in both groups at baseline and 3 months. In contrast, at 6 months the differences showed statistical significance $\left(P \_0.001\right)$ in favor of silk fibroin group. This might be due to greater bone formation around and on the implant surface as reported in previous studies ${ }^{(27,33)}$

\section{CONCLUSIONS}

Within the limitations of this study and according to included result, it can be concluded that:

Compared to PRF alone, adding silk fibroin might provide a better reconstruction of ridge width, implant stability and bone density in the narrow ridge augmented with crest splitting and immediate implants. 


\section{RECOMMENDATIONS}

Further studies are needed to assess the efficacy of silk fibroin as biological scaffold in periodontal regenerative procedures and implant dentistry.

\section{REFERENCES}

1. Leonhardt Å, Gröndahl K, Bergström C, Lekholm U. Long-term follow-up of osseointegrated titanium implants using clinical, radiographic and microbiological parameters. Clinical oral implants research. 2002;13(2):127-32.

2. Vierra M, Mau L, Huynh-Ba G, Schoolfield J, Cochran D. A lateral ridge augmentation study to evaluate a synthetic membrane for guided bone regeneration: an experiment in the canine mandible. Clinical oral implants research. 2016;27(1):73-82.

3. Starch-Jensen T, Becktor J. Maxillary Alveolar Ridge Expansion with Split-Crest Technique Compared with Lateral Ridge Augmentation with Autogenous Bone Block Graft: a Systematic Review. Ejournal of Oral and Maxillofacial Research. 2019;10(4).

4. Garcez-Filho J, Tolentino L, Sukekava F, Seabra M, Cesar-Neto J, Araújo M. Long-term outcomes from implants installed by using split-crest technique in posterior maxillae: 10 years of follow-up. Clinical oral implants research. 2015;26(3):326-31.

5. Nentwig G. Technic of bone splitting for alveolar recession in anterior maxillary region. Die Quintessenz. 1986;37(11): 1825 .

6. Pereira C, Gealh W, Meorin-Nogueira L, Garcia-Júnior I, Okamoto R. Piezosurgery applied to implant dentistry: clinical and biological aspects. Journal of Oral Implantology. 2014;40(S1):401-8.

7. Hamzacebi B, Oduncuoglu B, Alaaddinoglu E. Treatment of Peri-implant Bone Defects with Platelet-Rich Fibrin. International Journal of Periodontics \& Restorative Dentistry. 2015;35(3).

8. Lee J, Kim S, Kim J, Lee Y, Choi J, Dragos R, et al. Restoration of a peri-implant defect by platelet-rich fibrin. Oral surgery, oral medicine, oral pathology and oral radiology. 2012;113(4):459-63.

9. Chang Y, Yu H, Huang F. Anterior maxillary ridge splitting with simultaneous implant placement using platelet-rich fibrin as the sole grafting material. Journal of Dental Sciences. 2016;11(1):110.

10. Kaigler D, Avila G, Wisner-Lynch L, Nevins M, Nevins M, Rasperini G, et al. Platelet-derived growth factor appli- cations in periodontal and peri-implant bone regeneration. Expert opinion on biological therapy. 2011;11(3):375-85.

11. Zaki S, Mohamed S, Hommos A, El Ashwah A. study OF the effect of the compination of Platalat-rich fibrin (PRF) and allogenous bone graft around immediate implantes. Alexandria Dental Journal. 2017;42(2):127-34.

12. Miron RJ, Zucchelli G, Pikos MA, Salama M, Lee S, Guillemette $\mathrm{V}$, et al. Use of platelet-rich fibrin in regenerative dentistry: a systematic review. Clinical oral investigations. 2017;21(6):1913-27.

13. Borie E, Oliví D, Orsi I, Garlet K, Weber B, Beltrán V, et al. Platelet-rich fibrin application in dentistry: a literature review. International journal of clinical and experimental medicine. 2015;8(5):7922.

14. Goyal M, Mittal N, Gupta G, Singhal M. Ridge augmentation in implant dentistry. Journal of the International Clinical Dental Research Organization. 2015;7(3):94.

15. Kwon K, Seok H. Silk Protein-Based Membrane for Guided Bone Regeneration. Applied Sciences. 2018;8(8):1214.

16. Pritchard E, Valentin T, Boison D, Kaplan D. Incorporation of proteinase inhibitors into silk-based delivery devices for enhanced control of degradation and drug release. Biomaterials. 2011;32(3):909-18.

17. Joly P, Duda G, Schöne M, Welzel P, Freudenberg U, Werner $\mathrm{C}$, et al. Geometry-driven cell organization determines tissue growths in scaffold pores: consequences for fibronectin organization. PloS one. 2013;8(9):e73545.

18. Tolstunov L. Classification of the alveolar ridge width: implant-driven treatment considerations for the horizontally deficient alveolar ridges. Journal of Oral Implantology. 2014;40(S1):365-70.

19. Cristache C. Presurgical Cone Beam Computed Tomography Bone Quality Evaluation for Predictable Immediate Implant Placement and Restoration in Esthetic Zone. Case reports in dentistry. 2017;2017.

20. Guobis Z, Pacauskiene I, Astramskaite I. General diseases influence on peri-implantitis development: a systematic review. Journal of oral \& maxillofacial research. 2016;7(3).

21. Bryce G, Bomfim D, Bassi G. Pre-and post-operative management of dental implant placement. Part 1: management of post-operative pain. British dental journal. 2014;217(3):123.

22. Lee E, Gonzalez-Martin O, Fiorellini J. Lingualized flapless implant placement into fresh extraction sockets preserves buccal alveolar bone: a cone beam computed tomography study. Int J Periodontics Restorative Dent. 2014;34(1):61-8. 
23. Hasan I, Dominiak M, Blaszczyszyn A, Bourauel C, Gedrange T, Heinemann F. Radiographic evaluation of bone density around immediately loaded implants. Annals of Anatomy-Anatomischer Anzeiger. 2015;199:52-7.

24. Dohan Ehrenfest D, de Peppo G, Doglioli P, Sammartino G. Slow release of growth factors and thrombospondin-1 in Choukroun's platelet-rich fibrin (PRF): a gold standard to achieve for all surgical platelet concentrates technologies. Growth Factors. 2009;27(1):63-9.

25. Luo J, Zhang H, Cui X, Gao J, Wang X, Xiong J. 3-D mineralized silk fibroin/polycaprolactone composite scaffold modified with polyglutamate conjugated with BMP-2 peptide for bone tissue engineering. Colloids and surfaces B: Biointerfaces. 2018;163:369-78.

26. Jung S. Bioactive glass scaffolds, and method of making. Google Patents; 2019.

27. Jang E, Park J, Kweon H, Lee K, Kang S, Baek D, et al. Restoration of peri-implant defects in immediate implant installations by Choukroun platelet-rich fibrin and silk fibroin powder combination graft. Oral Surgery, Oral Medicine, Oral Pathology, Oral Radiology, and Endodontology. 2010;109(6):831-6.

28. Elnayef B, Monje A, Lin G, Gargallo-Albiol J, Chan H, Wang $\mathrm{H}$, et al. Alveolar ridge split on horizontal bone aug- mentation: a systematic review. International Journal of Oral \& Maxillofacial Implants. 2015;30(3).

29. Waechter J, Leite F, Nascimento G, Carmo Filho L, Faot F. The split crest technique and dental implants: a systematic review and meta-analysis. International journal of oral and maxillofacial surgery. 2017;46(1):116-28.

30. Cortese A, Pantaleo G, Amato M, Howard C, Pedicini L, Claudio P. Platelet-rich fibrin (PRF) in implants dentistry in combination with new bone regenerative flapless technique: evolution of the technique and final results. Open Medicine. 2017;12(1):24-32.

31. Song J, Kweon H, Kwon K, Park Y, Kim S. The bone regenerative effect of silk fibroin mixed with platelet-rich fibrin (PRF) in the calvaria defect of rabbit. Journal of the Korean Association of Oral and Maxillofacial Surgeons. 2010;36(4):250-4.

32. Lee E, Kim J, Kweon H, Jo Y, Min S, Park Y, et al. A combination graft of low-molecular-weight silk fibroin with Choukroun platelet-rich fibrin for rabbit calvarial defect. Oral Surgery, Oral Medicine, Oral Pathology, Oral Radiology, and Endodontology. 2010;109(5):e33-e8.

33. Öncü E, Alaaddinoglu E. The effect of platelet-rich fibrin on implant stability. International Journal of Oral \& Maxillofacial Implants. 2015;30(3). 